\title{
On the Variations of Some Well Known Fixed Point Theorem in Metric Spaces
}

\author{
Krishna Patel*, G M Deheri \\ Department of Mathematics, Sardar Patel University, Anand, Gujarat, India \\ *Corresponding author: krishnappatel10@gmail.com \\ Received April 20, 2015; Revised May 25, 2015; Accepted June 28, 2015
}

\begin{abstract}
Results dealing with a Fixed Point for a map need not be continuous on a metric space, which improves a famous classical result, has been presented here, wherein the convergence aspect is duly addressed. This paper aims to present some fixed point theorems on metric spaces. It can be easily observed that these are significant improvement of some of the well-known classical result dealing with the generalization of Banach fixed point theorem. Further, here the rate of convergence aspects is duly taken care of.
\end{abstract}

Keywords: fixed point, metric space, sequential convergent, subsequential convergent, uniqueness

Cite This Article: Krishna Patel, and G M Deheri, "On the Variations of Some Well Known Fixed Point Theorem in Metric Spaces." Turkish Journal of Analysis and Number Theory, vol. 3, no. 2 (2015): 70-74. doi: 10.12691/tjant-3-2-7.

\section{Introduction}

The fixed point theorem most frequently cited in literature is Banach contraction principle, which asserts that if $(X, d)$ is a complete metric space and $T: X \rightarrow X$ is a contractive mapping ( $T$ is contractive if there exist $\lambda \in[0,1) \quad$ such that for all $x, y \in X$, $d(T x, T y) \leq \lambda d(x, y))$ then $T$ has a unique fixed point.

In 1968, Kannan [3] established a fixed point $T$ for mapping satisfying:

$$
d(T x, T y) \leq \lambda[d(x, T x)+d(y, T y)]
$$

for $\lambda \in[0,1 / 2)$ and for all $x, y \in X$

Kannan's paper [3] dealing with the generalization of Banach fixed point theorem was followed by a spate of papers containing a variety of contractive definitions in metric spaces.

Rhodes [6] considered 250 types of contractive definitions and analyzed the interrelation among them.

Jungck and Rhoades [8] introduced the concept of weakly compatible maps for extending some well known fixed point theorems to the setting of set valued non continuous functions. Here the fixed point theorems were proved for set valued functions without appealing to the continuity.

In 2008 Azam and Arshad [1] extended Kannan's theorem for the generalized metric space introduced by Branciari [2] by replacing triangular inequality by rectangular one in the context of fixed point theorem.

In 2010 Moradi and Beiranvand [7] and Moardi and Omid [5] introduced new classes of contractive functions as following and established the Banach contraction principle.

\subsection{Definition}

Let $(X, d)$ be a metric space. A mapping $T: X \rightarrow X$ is said to be sequentially convergent if we have, for every sequence $\left\{y_{n}\right\}$, if $\left\{T y_{n}\right\}$ is convergent then $\left\{y_{n}\right\}$ is also convergent. $T$ is said to be subsequentially convergent if we have, for every sequence $\left\{y_{n}\right\}$, if $\left\{T y_{n}\right\}$ is convergent then $\left\{y_{n}\right\}$ has a convergent subsequence.

In 2011, Moradi and Alimohammadi [4] extended the Kannan's theorem and the theorem due to Azam and Arshad [1] as following:

\subsection{Theorem}

Let $(X, d)$ be a complete metric space and $T, S: X \rightarrow X$ be mappings such that $T$ is continuous, one- to- one and subsequentially convergent. If $\lambda \in[0,1 / 2)$ and for all $x, y \in X$

$$
d(T S x, T S y) \leq \lambda[d(T x, T S x)+d(T y, T S y)]
$$

then $S$ has a unique fixed point. Also if $T$ is sequentially convergent then for every $x_{0} \in X$ the sequence of iterates $\left\{S^{n} x_{0}\right\}$ converges to this fixed point.

In the present paper, sufficient conditions were obtained for the existence of the unique fixed point of Kannan's type mapping on complete metric spaces depending on another function. Of course, a variation of this aspect has been discussed by Patel and Deheri [9] in 2013 where 
common fixed point theorems were proved in the light of another function. Of course, the underlying spaces were Banach spaces.

Indeed, It has been deemed proper to provide some generalizations and variations of the main results presented in Moradi and Alimohammadi [5].

\section{Main Results}

The main result of the paper is contained in

\subsection{Theorem}

Let $(X, d)$ be a complete metric space and $T, S: X \rightarrow X$ be mappings such that $T$ is continuous, one- to- one and subsequentially convergent. If $\lambda \in[0,1 / 2)$ and for all $x, y \in X$

$$
d(T S x, T S y) \leq \lambda[d(T x, T S y)+d(T y, T S x)]
$$

then $S$ has a unique fixed point. Also if $T$ is sequentially convergent then for every $x_{0} \in X$ the sequence of iterates $\left\{S^{n} x_{0}\right\}$ converges to this fixed point.

Proof Let $x_{0} \in X$ be an arbitrary point in $X$. We define the iterative sequence $\left\{x_{n}\right\}$ by $x_{n+1}=S x_{n}$ (equivalently, $\left.x_{n}=S^{n} x_{0}\right), n=1,2,3 \ldots$.Using equation (1) one gets

$$
\begin{aligned}
d\left(T x_{n}, T x_{n+1}\right) & =d\left(T S x_{n-1}, T S x_{n}\right) \\
& \leq \lambda\left[d\left(T x_{n-1}, T S x_{n}\right)+d\left(T x_{n}, T S x_{n-1}\right)\right]
\end{aligned}
$$

leading to

$$
d\left(T x_{n}, T x_{n+1}\right) \leq\left(\frac{\lambda}{1-\lambda}\right) d\left(T x_{n-1}, T x_{n}\right)
$$

Using induction and equation (3), one finds that

$$
d\left(T x_{n}, T x_{n+1}\right) \leq\left(\frac{\lambda}{1-\lambda}\right)^{n} d\left(T x_{0}, T x_{1}\right)
$$

By (4), for every $m, n \in \mathbb{N}$ such that $m>n$ one obtains

$$
\begin{aligned}
d( & \left.T x_{m}, T x_{n}\right) \\
\leq & d\left(T x_{m}, T x_{m-1}\right)+d\left(T x_{m-1}, T x_{m-2}\right) \\
& +\cdots+d\left(T x_{n+1}, T x_{n}\right) \\
\leq & {\left[\left(\frac{\lambda}{1-\lambda}\right)^{m-1}+\left(\frac{\lambda}{1-\lambda}\right)^{m-2}+\cdots\right.} \\
\leq & {\left[\left(\frac{\lambda}{1-\lambda}\right)^{n}+\left(\frac{\lambda}{1-\lambda}\right)^{n+1}+\cdots\right] } \\
= & \left(\frac{\lambda}{1-\lambda}\right)^{n} \frac{1}{\left.1-\left(\frac{\lambda}{1-\lambda}\right)^{n}\right] d\left(T x_{0}, T x_{1}\right)} d\left(T x_{0}, T x_{1}\right)
\end{aligned}
$$

Letting $m, n \rightarrow \infty$ in equation (5) one concludes that $\left\{T x_{n}\right\}$ is a Cauchy sequence, and since $X$ is a complete metric space, there exists $v \in X$ such that

$$
\lim _{n \rightarrow \infty} T x_{n}=v
$$

Since $T$ is a subsequentially convergent, $\left\{x_{n}\right\}$ has a convergent subsequence. So there exists $u \in X$ and $\left\{x_{n(k)}\right\}_{k=1}^{\infty}$ such that $\lim _{k \rightarrow \infty} x_{n(k)}=u$. Since $T$ is continuous and $\lim _{k \rightarrow \infty} x_{n(k)}=u, \lim _{k \rightarrow \infty} T x_{n(k)}=T u$.

By equation (6) one gets that $T u=v$, which results in

$$
\begin{aligned}
& d(T S u, T u) \\
& \quad \leq d\left(T S u, T S^{n(k)} x_{0}\right)+d\left(T S^{n(k)} x_{0}, T S^{n(k)+1} x_{0}\right) \\
& \quad+d\left(T S^{n(k)+1} x_{0}, T u\right) \\
& \quad \leq \lambda\left[d\left(T u, T S x_{n(k)-1}\right)+d\left(T x_{n(k)-1}, T S u\right)\right] \\
& \quad+d\left(T x_{n(k)+1}, T u\right)+\left(\frac{\lambda}{1-\lambda}\right)^{n(k)} d\left(T x_{0}, T x_{1}\right) \\
& \quad \lambda d\left(T u, T S x_{n(k)-1}\right)+\lambda d\left(T x_{n(k)-1}, T S u\right) \\
& \quad+d\left(T x_{n(k)+1}, T u\right)+\left(\frac{\lambda}{1-\lambda}\right)^{n(k)} d\left(T x_{0}, T x_{1}\right)
\end{aligned}
$$

Letting $k \rightarrow \infty$ in equation (7) one gets

$$
d(T S u, T u) \leq \lambda d(T S u, T u) .
$$

This implies $d(T S u, T u)=0$.

Since $T$ is one-to-one $S u=u$ and $S$ has a fixed point.

\section{Uniqueness}

For the uniqueness of the fixed point let us assume that there are $u_{1}$ and $u_{2}$ in $X,\left(u_{1} \neq u_{2}\right)$ such that $S u_{1}=u_{1}$ and $S u_{2}=u_{2}$.

Then by equation (1) one get

$$
d\left(T S u_{1}, T S u_{2}\right) \leq \lambda\left[d\left(T u_{1}, T S u_{2}\right)+d\left(T u_{2}, T S u_{1}\right)\right]
$$

implies

$$
d\left(T u_{1}, T u_{2}\right) \leq 2 \lambda d\left(T u_{1}, T u_{2}\right)
$$

Since $T$ is one-to-one and $\lambda \in[0,1 / 2)$ one finds

$$
u_{1}=u_{2} \text {. }
$$

Also, if $T$ is sequentially convergent, by replacing $\{n\}$ with $\{n(k)\}$ we conclude that $\lim _{n \rightarrow \infty} x_{n}=u$ and this shows that $\left\{x_{n}\right\}$ converges to the fixed point of $S$.

To understand the importance of this result one can cast a glance at the following:

\subsection{Example}

Let $X=\{0\} \cup\left\{\frac{1}{4}, \frac{1}{5}, \frac{1}{6}, \ldots\right\} \quad$ endowed with the Euclidean metric. Define $S: X \rightarrow X$ by $S(0)=0$ and 
$S\left(\frac{1}{n}\right)=\frac{1}{n+1}$ for all $n \geq 4$. Obviously the condition in

Kannan's theorem is not true for every $\lambda>0$. So we cannot use Kannan's theorem. By defining $T: X \rightarrow X$ by $T(0)=0$ and $T\left(\frac{1}{n}\right)=\frac{1}{n^{n}}$ for all $n \geq 4$ one have, for $m, n \in \mathbb{N}(m>n)$,

$$
\begin{aligned}
\left|T S\left(\frac{1}{m}\right)-T S\left(\frac{1}{n}\right)\right| & =\frac{1}{(n+1)^{n+1}}-\frac{1}{(m+1)^{m+1}} \\
& <\frac{1}{(n+1)^{n+1}} \\
& \leq \frac{1}{3}\left[\frac{1}{n^{n}}-\frac{1}{(n+1)^{n+1}}\right] \\
& \leq \frac{1}{3}\left[\frac{1}{n^{n}}-\frac{1}{(n+1)^{n+1}}+\frac{1}{m^{m}} \frac{1}{(m+1)^{m+1}}\right] \\
& =\frac{1}{3}\left[\left|T\left(\frac{1}{n}\right)-T S\left(\frac{1}{m}\right)\right|+\left|T\left(\frac{1}{m}\right)-T S\left(\frac{1}{n}\right)\right|\right]
\end{aligned}
$$

Therefore, by theorem 2.1

$S$ has a unique fixed point $u=0$

Now, a little variation in the inequality of above result leads to:

\subsection{Theorem}

Let $(X, d)$ be a complete metric space and $T, S: X \rightarrow X$ be mappings such that $T$ is continuous, one- to- one and subsequentially convergent. If $\lambda \in[0,1 / 3)$ and for all $x, y \in X$

$$
d(T S x, T S y) \leq \lambda[d(T x, T S x)+d(T y, T S y)+d(T x, T y)](8)
$$

then $S$ has a unique fixed point. Also if $T$ is sequentially convergent then for every $x_{0} \in X$ the sequence of iterates $\left\{S^{n} x_{0}\right\}$ converges to this fixed point.

Proof Let $x_{0} \in X$ be an arbitrary point in $X$. We define the iterative sequence $\left\{x_{n}\right\}$ by $x_{n+1}=S x_{n}$ (equivalently, $x_{n}=S^{n} x_{0}$ ), $n=1,2,3 \ldots$.Using equation (8) one gets

$$
\begin{aligned}
d\left(T x_{n}, T x_{n+1}\right) & =d\left(T S x_{n-1}, T S x_{n}\right) \\
\leq & \lambda\left[d\left(T x_{n-1}, T S x_{n-1}\right)+d\left(T x_{n}, T S x_{n}\right)\right. \\
& \left.+d\left(T x_{n-1}, T x_{n}\right)\right]
\end{aligned}
$$

leading to

$$
d\left(T x_{n}, T x_{n+1}\right) \leq\left(\frac{2 \lambda}{1-\lambda}\right) d\left(T x_{n-1}, T x_{n}\right)
$$

Using induction and equation (10), one finds that

$$
d\left(T x_{n}, T x_{n+1}\right) \leq\left(\frac{2 \lambda}{1-\lambda}\right)^{n} d\left(T x_{0}, T x_{1}\right)
$$

By equation (11), for every $m, n \in \mathbb{N}$ such that $m>n$ one obtains

$$
\begin{aligned}
d( & \left(x_{m}, T x_{n}\right) \\
\leq & d\left(T x_{m}, T x_{m-1}\right)+d\left(T x_{m-1}, T x_{m-2}\right) \\
& +\cdots+d\left(T x_{n+1}, T x_{n}\right) \\
\leq & {\left[\left(\frac{\lambda}{1-\lambda}\right)^{m-1}+\left(\frac{\lambda}{1-\lambda}\right)^{m-2}+\cdots\right.} \\
\leq & {\left[\left(\frac{\lambda}{1-\lambda}\right)^{n}+\left(\frac{\lambda}{1-\lambda}\right)^{n+1}+\cdots\right] } \\
= & \left(\frac{\lambda}{1-\lambda}\right)^{n} \frac{1}{\left.1-\left(\frac{\lambda}{1-\lambda}\right)^{n}\right] d\left(T x_{0}, T x_{1}\right)} d\left(T x_{0}, T x_{1}\right)
\end{aligned}
$$

Letting $m, n \rightarrow \infty$ in equation (12) one concludes that $\left\{T x_{n}\right\}$ is a Cauchy sequence, and since $X$ is a complete metric space, there exists $v \in X$ such that

$$
\lim _{n \rightarrow \infty} T x_{n}=v
$$

Since $T$ is a subsequentially convergent, $\left\{x_{n}\right\}$ has a convergent subsequence. So there exists $u \in X$ and $\left\{x_{n(k)}\right\}_{k=1}^{\infty}$ such that $\lim _{k \rightarrow \infty} x_{n(k)}=u$. Since $T$ is continuous and $\lim _{k \rightarrow \infty} x_{n(k)}=u, \lim _{k \rightarrow \infty} T x_{n(k)}=T u$.

By equation (13) one gets that $T u=v$, which leads to

$$
\begin{aligned}
& d(T S u, T u) \\
& \quad \leq d\left(T S u, T S^{n(k)} x_{0}\right)+d\left(T S^{n(k)} x_{0}, T S^{n(k)+1} x_{0}\right) \\
& \quad+d\left(T S^{n(k)+1} x_{0}, T u\right) \\
& \quad \leq \lambda\left[\begin{array}{l}
d(T u, T S u) \\
+d\left(T x_{n(k)-1}, T S x_{n(k)-1}\right)+d\left(T u, T x_{n(k)-1}\right)
\end{array}\right] \\
& +\left(\frac{2 \lambda}{1-\lambda}\right)^{n(k)} d\left(T x_{0}, T x_{1}\right)+d\left(T x_{n(k)+1}, T u\right) \\
& \quad \leq \lambda d(T u, T S u)+\lambda\left(\frac{2 \lambda}{1-\lambda}\right)^{n(k)} d\left(T x_{0}, T x_{1}\right) \\
& \quad+\lambda d\left(T u, T x_{n(k)}\right)+\left(\frac{2 \lambda}{1-\lambda}\right)^{n(k)} d\left(T x_{0}, T x_{1}\right)
\end{aligned}
$$

hence,

$$
\begin{aligned}
d(T S u, T u) & \leq\left(\frac{1+\lambda}{1-\lambda}\right)\left(\frac{2 \lambda}{1-\lambda}\right)^{n(k)} d\left(T x_{0}, T x_{1}\right) \\
& +\left(\frac{1}{1-\lambda}\right) d\left(T x_{n(k)+1}, T u\right) \\
& +\left(\frac{\lambda}{1-\lambda}\right) d\left(T u, T x_{n(k)}\right)
\end{aligned}
$$

Letting $k \rightarrow \infty$ in equation (14) one gets

$$
d(T S u, T u)=0 .
$$

Since $T$ is one-to-one $S u=u$ and $S$ has a fixed point. 


\section{Uniqueness}

For the uniqueness of the fixed point let us assume that there are $u_{1}$ and $u_{2}$ in $X,\left(u_{1} \neq u_{2}\right)$ such that $S u_{1}=u_{1}$ and $S u_{2}=u_{2}$.

Then by equation (8) one obtains

$$
\begin{aligned}
& d\left(T S u_{1}, T S u_{2}\right) \\
& \quad \leq \lambda\left[d\left(T u_{1}, T S u_{1}\right)+d\left(T u_{2}, T S u_{2}\right)+d\left(T u_{1}, T u_{2}\right)\right]
\end{aligned}
$$

which implies that

$$
d\left(T u_{1}, T u_{2}\right) \leq \lambda d\left(T u_{1}, T u_{2}\right) .
$$

Since $T$ is one-to-one and $\lambda \in[0,1 / 3)$ one finds

$$
u_{1}=u_{2} \text {. }
$$

Also if $T$ is sequentially convergent, by replacing $\{n\}$ with $\{n(k)\}$ we conclude that $\lim _{n \rightarrow \infty} x_{n}=u$ and this shows that $\left\{x_{n}\right\}$ converges to the fixed point of $S$.

The following result marks the end of the discussion:

\subsection{Theorem}

Let $(X, d)$ be a complete metric space and $T, S: X \rightarrow X$ be mappings such that $T$ is continuous, one- to- one and subsequentially convergent. If $\lambda \in[0,1 / 3)$ and for all $x, y \in X$

$$
d(T S x, T S y) \leq \lambda\left[\begin{array}{l}
d(T x, T S y) \\
+d(T y, T S x)+d(T x, T y)
\end{array}\right]
$$

then $S$ has a unique fixed point. Also if $T$ is sequentially convergent then for every $x_{0} \in X$ the sequence of iterates $\left\{S^{n} x_{0}\right\}$ converges to this fixed point.

Proof Let $x_{0}$ be an arbitrary point in $X$. We define the iterative sequence $\left\{x_{n}\right\}$ by $x_{n+1}=S x_{n}$ (equivalently, $\left.x_{n}=S^{n} x_{0}\right) \quad n=1,2,3, \ldots$.Using equation (15) one gets

$$
\begin{aligned}
& d\left(T x_{n}, T x_{n+1}\right) \\
& \quad=d\left(T S x_{n-1}, T S x_{n}\right) \\
& \quad \leq \lambda\left[d\left(T x_{n-1}, T S x_{n}\right)+d\left(T x_{n}, T S x_{n-1}\right)+d\left(T x_{n-1}, T x_{n}\right)\right] \\
& \quad \leq \lambda\left[d\left(T x_{n-1}, T x_{n}\right)+d\left(T x_{n}, T x_{n+1}\right)+d\left(T x_{n}, T x_{n-1}\right)\right]
\end{aligned}
$$

(16)

leading to

$$
d\left(T x_{n}, T x_{n+1}\right) \leq\left(\frac{2 \lambda}{1-\lambda}\right) d\left(T x_{n-1}, T x_{n}\right)
$$

Using induction and equation (17), one finds that

$$
d\left(T x_{n}, T x_{n+1}\right) \leq\left(\frac{2 \lambda}{1-\lambda}\right)^{n} d\left(T x_{0}, T x_{1}\right)
$$

By equation (18), for every $m, n \in \mathbb{N}$ such that $m>n$ one obtains

$$
\begin{aligned}
& d\left(T x_{m}, T x_{n}\right) \\
& \leq d\left(T x_{m}, T x_{m-1}\right)+d\left(T x_{m-1}, T x_{m-2}\right) \\
&+\cdots+d\left(T x_{n+1}, T x_{n}\right) \\
& \leq {\left[\left(\frac{\lambda}{1-\lambda}\right)^{m-1}+\left(\frac{\lambda}{1-\lambda}\right)^{m-2}+\cdots\right.} \\
&\left.\cdots+\left(\frac{\lambda}{1-\lambda}\right)^{n}\right] d\left(T x_{0}, T x_{1}\right) \\
& \leq \\
& \quad\left[\left(\frac{\lambda}{1-\lambda}\right)^{n}+\left(\frac{\lambda}{1-\lambda}\right)^{n+1}+\cdots\right] \\
&=\left(\frac{\lambda}{1-\lambda}\right)^{n} \frac{1}{1-\left(\frac{\lambda}{1-\lambda}\right)} d\left(T x_{0}, T x_{1}\right)
\end{aligned}
$$

Letting $m, n \rightarrow \infty$ in equation (19) one concludes that $\left\{T x_{n}\right\}$ is a Cauchy sequence, and since $X$ is a complete metric space, there exists $v \in X$ such that

$$
\lim _{n \rightarrow \infty} T x_{n}=v
$$

Since $T$ is a subsequentially convergent, $\left\{x_{n}\right\}$ has a convergent subsequence. So there exists $u \in X$ and $\left\{x_{n(k)}\right\}_{k=1}^{\infty}$ such that $\lim _{k \rightarrow \infty} x_{n(k)}=u$. Since $T$ is continuous and $\lim _{k \rightarrow \infty} x_{n(k)}=u, \lim _{k \rightarrow \infty} T x_{n(k)}=T u$.

By equation (20) one gets that $T u=v$, which results in

$$
\begin{aligned}
& d(T S u, T u) \\
& \quad \leq d\left(T S u, T S^{n(k)} x_{0}\right)+d\left(T S^{n(k)} x_{0}, T S^{n(k)+1} x_{0}\right) \\
& \quad+d\left(T S^{n(k)+1} x_{0}, T u\right) \\
& \quad \leq \lambda\left[d\left(T u, T S x_{n(k)-1}\right)+d\left(T x_{n(k)-1}, T S u\right)\right. \\
& \left.\quad+d\left(T u, T x_{n(k)}\right)\right]+\left(\frac{2 \lambda}{1-\lambda}\right)^{n(k)} d\left(T x_{0}, T x_{1}\right) \\
& \quad+d\left(T x_{n(k)+1}, T u\right)
\end{aligned}
$$

Letting $k \rightarrow \infty$ in equation (21) one gets

$$
d(T S u, T u) \leq \lambda d(T S u, T u) .
$$

This implies $d(T S u, T u)=0$.

Since $T$ is one-to-one $S u=u$ and $S$ has a fixed point.

\section{Uniqueness}

For the uniqueness of the fixed point let us assume that there are $u_{1}$ and $u_{2}$ in $X,\left(u_{1} \neq u_{2}\right)$ such that $S u_{1}=u_{1}$ and $S u_{2}=u_{2}$.

Then by equation (15) one obtains

$$
d\left(T S u_{1}, T S y\right) \leq \lambda\left[\begin{array}{l}
d\left(T u_{1}, T S u_{2}\right) \\
+d\left(T u_{2}, T S u_{1}\right) \\
+d\left(T u_{1}, T u_{2}\right)
\end{array}\right]
$$

which implies that

$$
d\left(T u_{1}, T u_{2}\right) \leq 3 \lambda d\left(T u_{2}, T u_{1}\right)
$$


Since $T$ is one-to-one and $\lambda \in[0,1 / 3)$ one finds

$$
u_{1}=u_{2}
$$

Also, if $T$ is sequentially convergent, by replacing $\{n\}$ with $\{n(k)\}$ we conclude that $\lim _{n \rightarrow \infty} x_{n}=u$ and this shows that $\left\{x_{n}\right\}$ converges to the fixed point of $S$.

\section{Conclusion}

As can be seen the results presented here not only are far more generalized version, but also improve some of the well known classical results, addressing convergence intervals.

\section{Acknowledgement}

The corresponding author acknowledges the funding agency CSIR.

\section{References}

[1] Azam, A. and Arshad, M., "Kannan fixed point theorem on generalized metric spaces," The J. Nonlinear Sci. Appl., 1(1), 4548, Jul.2008.

[2] Branciari, A., "A fixed point theorem of Banach- Caccippoli type on a class of generalized metric spaces," Publ. Math. Debrecen, 57 (1-2), 31-37, 2000.

[3] Kannan, R.., "Some results on fixed points," Bull. Calcutta Math. Soc., 60, 71-76, 1968.

[4] Moradi, S. and Alimohammadi, D., "New extensions of Kannan fixed-point theorem on complete metric and generalized metric spaces," Int. Journal of math. Analysis, 5(47), 2313-2320, 2011.

[5] Moradi, S. and Omid, M., "A fixed point theorem for integral type inequality depending on another function," Int. J. Math. Anal., 4, 1491-1499, 2010.

[6] Rhoades, B. E., "A Comparison of Various Definitions of Contractive Mappings," Amer. Math. Soc., 226, 257-290,1977.

[7] Moradi, S. and Beiranvand, A., "Fixed Point of TF-contractive Single-valued Mappings," Iranian Journal of Mathematical sciences and informatics, 5, 25-32, 2010.

[8] Jungck, G. and Rhoades, B. E., "Fixed points for set valued functions without continuity", Indian J. pure appl. Math., 29(3), 227-238, March 1998

[9] Patel, K. and Deheri, G., "Extension of some common fixed point theorems", International Journal of Applied Physics and Mathematics, 3(5), 329-335, Sept.2013. 